\title{
The pack of Camel contains images that influence adolescents to become established smokers: $A$ three year follow-up
}

\author{
Raúl H. Sansores', Alejandra Ramírez-Venegas', Valeri Noé-Díaz', Leonor García-Gómez' \\ ' Instituto Nacional de Enfermedades Respiratorias (National Institute of Respiratory Diseases), Mexico
}

\begin{abstract}
RESUMEN
Introducción: el deseo de adquirir artículos promocionales de las compañías tabacaleras (receptividad) es un factor de riesgo asociado con convertirse en un fumador establecido. Existe la posibilidad de que la percepción de contenido sexual en la publicidad del tabaco (PCS) sea parte de ese deseo y actúe como un factor de riesgo adicional. Objetivo: el objetivo de este estudio fue determinar la influencia de la receptividad y PCS en el proceso de fumar. Método: en 1998, 1186 estudiantes de secundaria fueron encuestados para determinar su receptividad y PCS. Después de tres años, 303 de ellos fueron seguidos a través de una entrevista telefónica con el fin de correlacionar su estado actual de fumador con el antecedente previamente registrado de receptividad y PCS. Resultados: $62 \%$ de los sujetos eran receptivos y $78 \%$ percibe algún tipo de contenido sexual en la publicidad. Tanto la receptividad como PSC se asociaron significativamente con la probabilidad de convertirse en un fumador establecido (FE) (OR 2,36 [IC 95\% 2,36-1,18] y OR 2,56 [1,02-6,42], respectivamente). Discusión y conclusiones: receptividad y PCS son factores de riesgo independientes que pueden ocasionar que los adolescentes se conviertan en fumadores establecidos.
\end{abstract}

Palabras clave: inicio de consumo de tabaco; adolescentes; anuncios sexuales.

\begin{abstract}
Introduction: the desire to acquire promotional articles from tobacco companies (receptivity) is a risk factor associated with becoming an established smoker. There is a possibility that the perception of sexual content in tobacco advertising (PCS) may be part of that desire and act as an additional risk factor. Objective: the objective of this study was to determine the influence of receptivity and PCS in the smoking process. Method: in 1998, 1186 high school students were surveyed in order to determine their receptivity and PCS. After three years, 303 of them were followed through a telephone interview in order to correlate their current smoking status with the previously recorded antecedent of receptivity and PCS. Results: $62 \%$ of the subjects were receptive and $78 \%$ perceived some kind of sexual content in the advertising. Both receptivity and PCS were significantly associated with the probability of becoming an Established Smoker (ES) (OR 2.36 [95\% CI 2.36-1.18] and OR 2.56 [1.02-6.42] respectively). Discussion and conclusions: receptivity and PCS are independent risk factors than can cause teenagers to become established smokers.
\end{abstract}

Keywords: tobacco smoking initiation; adolescents; sexual advertisements.

\section{Corresponding author:}

Raul H. Sansores. Departamento de Investigación en Tabaquismo y EPOC, Instituto Nacional de Enfermedades Respiratorias Ismael Cosío Villegas. Calzada de Tlalpan, núm. 4502, col. Sección XVI, del. Tlalpan, C.P. 14080, Distrito Federal, Mexico. Phone and fax: +52(55) 5487 1742. E-mail: rhsansores@yahoo.com.mx.

Received: July 07, 2015.

Accepted: September 18, 2015.

DOI: 10.28931/riiad.2015.1.04 


\section{INTRODUCTION}

Nicotine addiction is the number one preventable cause of premature death in our society; it has been associated with an increasing number of illnesses (Thun \& Peto, 2012). Therefore, efforts should be focused on stimulating smokers to stop, and preventing children and adolescents from starting smoking. This issue is particularly relevant among teenagers due to the association between early tobacco use and the significantly minor cumulative probability of quitting in the future (Bowes, Chollet, Fombone \& Melchior, 2015). Studies indicate that tobacco smoking among youth is growing worldwide (Centers for Disease Control and Prevention [CDC], 2003). It has been estimated that, in Mexico, the average age of first use is 20 years or even younger (Secretaría de Salud [SSA], 2012; World Health Organization [WHO], 2013).

Tobacco companies have focused their promotional efforts on youngsters and women, particularly those from lower socioeconomic groups and developing countries because they represent an enormous market. To this group, specific tobacco publicity and advertising has been directed (CDC, 1988; Hanson \& Kyasar, 1999). An association between the promotional campaigns of tobacco companies and an acute rise in teenagers' use of tobacco, has been reported (Pierce, Lee, \& Gilpin, 1994; Pierce \& Gilpin, 1995). The probability of a teenager's smoking is greater if she/he is susceptible and/or receptive (Pierce, Choi, Gilpin, Farkas, \& Berry, 1998). However, little attention has been paid to the elements that determine that attraction of adolescents toward the advertising or promotional articles of the tobacco industry. The questions that underlie these facts are: why are adolescents so interested in these advertisements or promotional articles of the tobacco industry? Why are they so receptive to these messages? Our hypothesis is that tobacco promotions include sexual messages which are perceived by adolescents, inducing them to experiment with smoking and to eventually become established smokers.

The best example of attractive advertising with sexual content is Joe Camel. In a recent report of The Surgeon General (CDC, 2000) it was named as the Critical Example of publicity and regulations. Joe Camel was perhaps the most discussed tobacco promotion of the 1990's in the US. Assertions were made that the campaign targeted minors in order to attract them to cigarette smoking. The main criticism surrounding the cartoon character of Joe Came/ was that he had a substantial impact on under-aged youth who smoked (DiFranza et al. 1991; Fischer, Schwartz, Richards, Goldstein, \& Rojas, 1991). The ultimate consequence of a prolonged lawsuit against JC Reynolds was that, in 1997, they agreed to cease placing Joe Camel materials in magazines, newspapers and retail establishments. In 1998 a Master Settlement Agreement banned the use of all cartoon characters, including Joe Camel, in the advertising, promotion, packaging and labeling of any tobacco product. There was no doubt that Joe Camel had undertones and overtones with sexual character, although no specific studies were published on that subject.

Keeping in mind that the main interest of tobacco companies is increasing sales, and given the background of success associated with the subliminal advertising of Joe Camel, one can assume that the campaign has not finished yet. We have previously demonstrated (Sansores, Giraldo-Buitrago, Reddy, \& Ramírez-Venegas, 2002) that the camel used as a model in the current cigarette pack contains sexual images which are perceived by adolescents. Additionally, the perceptions of those images are associated with an increased probability of experimenting with cigarettes and/or becoming potentially established smokers.

In spite of the importance of our initial observations (Sansores et al., 2002), their cross-sectional design only allows us to make inferences about the future. Therefore, our current goal was to determine, after three years, the smoking status of those adolescents who had been receptive and perceived sexual content in the pack of Camel to some extent.

\section{METHOD}

\section{Design}

This study was undertaken in the Department of Research on Tobacco Smoking and COPD at the National Institute of Respiratory Diseases (INER) in Mexico City. A survey was administered to adolescents from public and private schools (September 1998-March 1999) to determine perception of sexual content (PSC) and receptivity of tobacco advertisements. After three years (April-May 2002) a second survey of all participants was conducted by phone to determine current smoking status and present status of susceptibility and receptivity in order to correlate them with baseline PSC. This research study was approved by the ethics committee of the INER. In addition, a letter of permission was obtained from the directors of the schools. This study was made feasible as part of a collaborative agreement between National Institute of Respiratory Diseases and the schools. Likewise, a guarantee of confidentiality was offered to students, parents and professors.

Participants were first grade high school students, aged between 12 to 14 years old. Each participant signed a consent form. If they had other different age, 
they were excluded. If questionnaire was incomplete subject was excluded.

\section{Procedures}

First wave

1186 teenagers completed the questionnaire. Before administering the questionnaire in their classrooms, the students were briefed on the survey and confidentiality by the researcher and the teacher. The questionnaire included items related to general data, current smoking status, smoking behavior of friends, and receptivity to promotions by the tobacco industry, seeking to assess the perception of sexual content of tobacco advertisements. Students were exposed to the advertisements by using slide projections before answering the questions.

\section{Second wave}

Three years after the first wave, a second similar survey was undertaken by telephone to determine current smoking status, susceptibility and receptivity. The reproducibility of those items was validated in two different interviews, at least one week apart from each other.

Smoking History and Susceptibility to Promotions by the Tobacco Industry. Based on the work of Pierce et al. (1998), a respondent was classified into one of four mutually exclusive categories: a) established smokers; b) experimenters; c) non-susceptible non-smokers; d) susceptible non-smokers. An established smoker was defined as an adolescent giving a positive response to the questions "Do you smoke?" and "Have you smoked at least 100 cigarettes in your life?" An experimenter was defined as an adolescent giving an affirmative response to either of the following questions: "Have you ever smoked a cigarette?" or "Have you ever tried or experimented with cigarette smoking, even only a few puffs?" A negative response to both of the questions categorized an adolescent as a non-smoker. A non-susceptible non-smoker was distinguished from other non-smokers by responses to the following 3 questions about future smoking: "Do you think you will try a cigarette soon?", "If one of your best friends asked you to smoke a cigarette, would you accept?", "At any time during the following year, do you think that you would smoke a cigarette?" The possible answers were "yes," "no," or "I don't know." To be classified as a non-susceptible non-smoker, the adolescent needed to respond "no" to all three questions. Any other response led to the adolescent's being categorized as susceptible to smoking.

Receptivity. Defined in the same terms used by Pierce and collaborators (1998), it is a measure of the individual tendency to use a promotional article of the to- bacco industry. Respondents were graded as being non-receptive, minimally receptive and highly receptive, according to their responses to the questions: "Have you ever bought or received an item that advertises a certain brand of cigarettes or that was distributed by a tobacco company?" and "Do you think that you would ever use a promotional article of the tobacco industry such as a T-shirt or a cap?" A respondent that was not receptive replied negatively to both questions. Minimal receptiveness was judged as a positive reply to one of the two questions, and high receptiveness was a positive reply to both questions.

Perception of Sexual Content in Advertisements (PSC). In order to determine the potential sexual content and its impact on advertising, the respondents were exposed for two minutes to two images of well-known cigarette brands: the "Marlboro" advertisement, in which a cowboy is smoking a cigarette and the traditional "Camel" advertisement, which shows a camel next to a pyramid. As in previous findings, the camel had an unquestionable sexual content, whereas the smoking cowboy was devoid of it. The images were projected in color onto a $1.5 \times 1.5 \mathrm{~m}$ screen and the impact of the commercial was evaluated at the same time in the questionnaire. Student responses were graded as absent, minimal and high perception of sexual content according to their answers to the questions: "Does the camel figure attract your attention?", "Do you believe that the camel figure contains any sexual content?" and "Do you think that the image of the camel contains a naked man and a naked woman?" A high perception of sexual content was a positive response to all three questions; a minimal perception was a positive response to one or two of the three questions, and a negative response to all three questions was equivalent to the absence of perception of sexual content. These images were used and widely described in a previous study (Sansores et al., 2002).

\section{Statistical Analysis}

Descriptive statistics were performed on all data and consisted of means and $95 \%$ confidence intervals for continuous variables, and frequency distributions for non-continuous variables. The association of factors affecting the status of experimental and established smokers was determined by binomial logistic regression analysis. Likewise, a similar model determined the factors associated with PSC.

\section{RESULTS}

Of the original 1186 students, only 507 completed their names and telephone numbers, and 303 were reached 
and interviewed twice the second time. As noted in Table 1 , their mean age in the second wave was $16 \pm 1 ; 178$ (59\%) were males and 124 (41\%) females. There were no significant differences between the original population and the sample from the second survey in terms of gender, receptivity, PSC and smoking status $\left(X^{2}=0.076\right.$, $p=0.782$ ). However, remarkable differences were observed in their smoking status. While the number of ES increased from $11 \%$ to $19 \%$, the number of susceptible non-smokers decreased from $16 \%$ to $7 \%$.

Table 2 shows the impact of receptivity and PSC on adolescents who were established smokers in the first wave $(n=27)$. When receptivity was present, $100 \%$ of the smokers kept smoking, $86 \%$ as ES and $14 \%$ as experimenters. When PSC was present, $84 \%$ continued as established smokers while $16 \%$ remained experimenters. Table 2 also shows that, in experimenters $(n=132)$, the presence or absence of receptivity did not influence their becoming in established smokers (18\% and $17 \%$ respectively). On the other hand, when PSC was present, $20 \%$ became ES whereas, in absence of PSC, only $7 \%$ of them turned into established smokers. The binomial logistic multiple regression analysis showed that both receptivity and PSC are significantly associated with the probability of becoming an established smoker [OR 2.36 (95\% Cl 2.36-1.18) and OR 2.56 (1.02-6.42) respectively.

This table shows that an important number of adolescents who were susceptible but had not smoked yet in $1998(n=75)$ became established smokers and were greatly influenced both by receptivity [20\% versus $7 \%$ (with or without receptivity respectively)] and PSC [17\% versus $6 \%$ (with or without PSC respectively)]. On the other hand,

Table 1

Characteristics of participants

\begin{tabular}{lccc}
\hline & $\begin{array}{c}\text { 1st wave } \\
\mathrm{n}=1186\end{array}$ & $\begin{array}{c}\text { 2nd wave } \\
\mathrm{n}=303\end{array}$ & $p$ \\
\hline $\begin{array}{c}\text { Gender } \\
\text { Male }\end{array}$ & $\mathrm{n}(\%)$ & $\mathrm{n}(\%)$ & \\
Receptivity & $732(62)$ & $178(59)$ & 0.06 \\
$\quad$ Present & $774(66)$ & $188(62)$ & $\mathrm{NS}$ \\
PSC & & & \\
Present & $902(77)$ & $237(78)$ & $\mathrm{NS}$ \\
Smoking status & & & $*$ \\
ES & $128(11)$ & $58(19)$ & $\mathrm{NS}$ \\
ExS & $509(43)$ & $126(42)$ & $\mathrm{NS}$ \\
SNS & $167(16)$ & $22(7)$ & $\mathrm{NS}$ \\
NSNS & $267(25)$ & $96(32)$ & NS \\
\hline
\end{tabular}

Note: ${ }^{*} \mathrm{X} 2=0.076, \mathrm{p}=0.782, \mathrm{PSC}=$ Perception of sexual content in advertisements, ES = Established smoker, ExS = Experimenters smoker, SNS $=$ Susceptible non-smoker, NSNS $=$ Non susceptible non-smoker among those who became experimenters by the second wave, no association with R nor PSC was found $(41 \%$ and $52 \%$ having been receptive or not, respectively, and $44 \%$ and $50 \%$ having had PSC or not, respectively).

The large majority of adolescents who were non-susceptible non-smokers in the first survey, $(n=69)$ continued as non-smokers in the second one. From the whole group, 68\% kept being NSNS whereas 10\% became susceptible but remained non-smokers. From the remaining group, most became experimenters and the presence of receptivity or PSC did not influence any trend.

\section{DISCUSSION AND CONCLUSIONS}

We determined the smoking status in adolescents who had been receptive and perceived sexual content in the pack of Camel after three years after of the baseline interview. The results of this work showed that receptivity to tobacco company promotions; in particular JC Reynolds with Camel, and the perception, to any extent, of sexual content in their advertisements, is significantly associated with the probability of an adolescent's becoming an established smoker in the future.

Of particular importance in this study is the influence of receptivity and PSC on 3 different variables: The first two of them are independent but related: 1) the progress observed in those adolescents who were susceptible but non-smokers and 2) the impact on the number of ES observed when adolescents are both receptive and perceptive. The third issue is the stable property of the concept of non-susceptible non-smoker. This aspect of our results must be highlighted, because NSNS adolescents kept away from smoking independently of the presence of receptivity or PSC. Of the 138 who were NSNS, only one of them (1.44\%) became ES and 14 (20\%) experimenters. In this group, no influence of receptivity or PSC was recorded.

The impact and co-influence of receptivity and PSC on the number of established smokers can be observed in Table 1. When an adolescent is not receptive and has no PSC, the chances of becoming an established smoker are zero. However, if he/she is receptive, the chances increase to being either susceptible or an experimenter. However, if he/she additionally has PSC, the chances are much higher.

Our data showed that, of those who are susceptible, $20 \%$ and $17 \%$ progressed to being ES (receptive or with PSC, respectively). This observation raises two additional insights. Firstly, why are adolescents susceptible? Recent investigations suggest that this is a matter of ethnicity, parental socioeconomic status, educational factors and lifestyle (Dell, Whitman, Shah, Silva, \& Ansell, 2005). Others suggest that promotional campaigns and advertisements are involved in this susceptibility. A more recent trend suggests that there is a genetic susceptibility to becoming 
Table 2

Course time of smoking status according to receptivity and perception of sexual content

\begin{tabular}{|c|c|c|c|c|c|}
\hline \multirow[t]{2}{*}{ Baseline smoking status 1st wave } & \multicolumn{5}{|c|}{ Current smoking status $2^{\text {nd }}$ wave } \\
\hline & $\begin{array}{c}\text { ES } \\
n(\%)\end{array}$ & $\begin{array}{c}\text { ExS } \\
n(\%)\end{array}$ & $\begin{array}{l}\text { SNS } \\
\mathrm{n}(\%)\end{array}$ & $\begin{array}{l}\text { NSNS } \\
\mathrm{n}(\%)\end{array}$ & Total \\
\hline \multicolumn{6}{|l|}{ Established smoker ( $n=27)$} \\
\hline \multicolumn{6}{|l|}{ Receptivity } \\
\hline Present & $19(86)$ & $3(14)$ & 0 & 0 & 22 \\
\hline Absent & $4(80)$ & $1(20)$ & 0 & 0 & 5 \\
\hline \multicolumn{6}{|l|}{ PSC } \\
\hline Present & $21(84)$ & $4(16)$ & 0 & 0 & 25 \\
\hline Absent & $2(100)$ & 0 & 0 & 0 & 2 \\
\hline \multicolumn{6}{|l|}{ Experimenter smoker $(n=132)$} \\
\hline \multicolumn{6}{|l|}{ Receptivity } \\
\hline Present & $16(18)$ & $51(56)$ & $6(7)$ & $17(19)$ & 90 \\
\hline Absent & $7(17)$ & $24(57)$ & $3(7)$ & $8(19)$ & 42 \\
\hline \multicolumn{6}{|l|}{ PSC } \\
\hline Present & $21(20)$ & $56(55)$ & $7(7)$ & $19(18)$ & 103 \\
\hline Absent & $2(7)$ & $19(65)$ & $2(7)$ & $6(21)$ & 29 \\
\hline \multicolumn{6}{|l|}{ Susceptible non-smoker $(n=75)$} \\
\hline \multicolumn{6}{|l|}{ Receptivity } \\
\hline Present & $9(20)$ & $19(41)$ & $3(6)$ & $15(33)$ & 46 \\
\hline Absent & $2(7)$ & $15(52)$ & $3(10)$ & $9(31)$ & 29 \\
\hline \multicolumn{6}{|l|}{ PSC } \\
\hline Present & $10(17)$ & $26(44)$ & $3(5)$ & $20(34)$ & 59 \\
\hline Absent & $1(6)$ & $8(50)$ & $3(19)$ & $4(25)$ & 16 \\
\hline \multicolumn{6}{|l|}{ Non susceptible non-smoker $(n=69)$} \\
\hline \multicolumn{6}{|l|}{ Receptivity } \\
\hline Present & $1(3)$ & $7(24)$ & $4(13)$ & $18(60)$ & 30 \\
\hline Absent & 0 & $7(18)$ & $3(8)$ & $29(74)$ & 39 \\
\hline \multicolumn{6}{|l|}{ PSC } \\
\hline Present & 0 & $10(20)$ & $6(12)$ & $34(68)$ & 50 \\
\hline Absent & $1(5)$ & $4(21)$ & $1(5)$ & 13 (69) & 19 \\
\hline
\end{tabular}

Note: ES = Established smoker, ExS = Experimenters smoker, SNS = Susceptible non-smoker, NSNS = Non susceptible non-smoker

a smoker (Munafo, Clark, Johnstone, Murphy, \& Walton, 2004). Secondly, independently of the etiology of this susceptibility, particular preventive programs are needed to identify and to educate these adolescents.

In 1991 Pierce and collaborators demonstrated that the Camel brand advertisements were effective and strongly influenced adolescents to start smoking. Subsequently, a longitudinal study (Pierce et al., 1998) reported that the odds ratio of progressing into an ES is 2.89. The results of the present study were similar to those data not only in terms of statistical analysis but also in design, as well as in the follow-up and instruments used to generate the information on receptivity. However, this study contributes beyond the current state of speculations on the factors re- lated to tobacco smoking in adolescents. This work shows that perception of sexual content is an independent risk factor that encourages adolescents to become established smokers. Our hypothesis is that adolescents perceive those messages because advertisements contain subliminal messages with sexual content that captivate their attention. DiFranza and collaborators (1991) proved that the Joe Camel image is highly successful as a promotional material among children. They also estimated that the profits from cigarette sales to minors rose from 6 million before Joe Camel's appearance in 1988, to 476 million dollars in 1991. In another study, Fischer and collaborators (1991) demonstrated that the attraction to Joe Camel showed up in children from age three. Their results 
also showed that as children grew up, the recognition and attraction index rose to $90 \%$. According to our hypothesis, this attraction takes place because of the sexual content of the advertisement and publicity of Joe Camel. We have previously demonstrated (Sansores et al., 2002) that 76\% of teenagers perceive a sexual content in the Camel pack. This finding would be meaningless if it had no relation to the smoking behavior by youth. The present findings show that there is an association between receptivity and smoking status. This PSC has an impact on adolescents, increasing the number of people who experiment with cigarettes and raising the number of established smokers.

A serious limitation of this study is the number of subjects. The adolescents that participated in this study (303) represent $26 \%$ of the original sample of 1186 . However, they are $60 \%$ of the participants who gave their telephone number correctly. On the other hand, the participants who were reached showed no significant differences in terms of gender, PSC and receptivity were observed (Table 1).

In summary, our results show that both receptivity and PSC are factors that could encourage youngsters to become established smokers. Therefore, tobacco advertisements should be critically evaluated, taking into account the possible subliminal contents that, according to our results, are perceived by adolescents.

\section{FUNDING SOURCE}

None.

\section{CONFLICT OF INTEREST}

The authors have no conflict of interest to declare regarding this study or the presented results.

\section{REFERENCES}

Bowes, L., Chollet, A., Fombone, E., \& Melchior, M. (2015). Psychological, social and familial factors associated with tobacco cessation among young adults. European Addiction Research, 21, 153-159.

Centers for Disease Control and Prevention. (2003). Tobacco use among middle and high school students--United States, 2002. MMWR. Morbidity and mortality weekly report, 52(45), 1096.

Centers for Disease Control and Prevention. (2000). Reducing Tobaco Use: A Report of the Surgeon General. Department and Human Service, Center for Disease Control and Prevention, National Center for Chronic Disease Prevention and Health Promotion, Office on Smoking and Health.

Centers for Disease Control and Prevention. (1988). Cigarette advertisements. Morbidity and Mortality Weekly Report, 39, 261-265.
Dell, J.L., Whitman, S., Shah, A.M., Silva, A., \& Ansell, D. (2005). Smoking in 6 diverse Chicago communities--a population study. American Journal of Public Health, 95, 1016-1023.

Difranza, J., Richards, J., Paulman, P.M., Wolf-Gillespie, N., Fletcher, C., Jaffe, R.D., \& Murray, D. (1991). Nabisco's cartoon camel promotes camel cigarettes to children. Journal of the American Medical Association, 266, 3149-3153.

Fischer, P.M., Schwartz, M.P., Richards, J.W., Goldstein, A.O., \& Rojas, T.H. (1991).Brand logo recognition by children aged 3 to 6 years. Mickey Mouse and Old Joe the Camel. Journal of the American Medical Association, 266, 3145-3148.

Hanson, J.D., \& Kyasar, D.A. (1999). Taking behavioralism seriously: some evidence of market manipulation. Harvard Law Review, 112, 1420-1572.

Munafo, M., Clark, T., Johnstone, E., Murphy, M., \& Walton, R. (2004). The genetic basis for smoking behavior: a systematic review and meta-analysis. Nicotine Tobacco Research, 6, 583-97.

Pierce, J.P., Choi, W.S., Gilpin, E.A., Farkas, A.J., \& Berry, C.C. (1998). Tobacco industry promotion of cigarettes and adolescent smoking. Journal of the American Medical Association, 279, 511-515.

Pierce, J.P., Gilpin, E., Burns, D.M., Whalen. E., Rosbrook, B., Shopland, D., \& Johnson, M. (1991). Does tobacco advertising target young people to start smoking? Evidence from California. Journal of the American Medical Association, 266, 3154-3158.

Pierce, J.P., Lee, L., \& Gilpin, E.A. (1994). Smoking initiation by adolescent girls, 1944 through 1988. An association with targeted advertising. Journal of the American Medical Association, 271, 608-611.

Pierce, J.P. \& Gilpin, E.A. (1995). A historical analysis of tobacco marketing and the uptake of smoking by youth in the United States: 1890-1977. Health Psychology, 14, 500-508.

Sansores, R.H., Giraldo-Buitrago, G., Reddy, C., \& Ramírez-Venegas, A. (2002). Sexual content of advertisements and the smoking process in adolescents. Chest, 121, 2016-2022.

Secretaría de Salud, Centro Nacional para la Prevención de las Adicciones, Comisión Nacional contra las Adicciones, Instituto Nacional de Salud Pública, Instituto Nacional de Psiquiatría. (2012). Encuesta Nacional de Adicciones 2011: Reporte de Tabaco. México: Secretaría de Salud. Centro Nacional para la Prevención de las Adicciones. Comisión Nacional contra las Adicciones. Instituto Nacional de Salud Pública. Instituto Nacional de Psiquiatría.

Thun, M., \& Peto, R., (2012). Stages of the cigarette epidemic on entering its second century. Tobacco Control, 21, 96-101.

World Health Organization. (2013). Report on Global Youth Tobacco Survey (GYTS) and Global School Personnel Survey (GSPS) in Mexico. Retrieved from: http://www. Mexico-National\%20 GYTS\%202011\%20Factsheet\%20(Ages\%2013-15)_Tag508.pdf 